\title{
The Phanerozoic diversification of silica-cycling testate amoebae and its possible links to changes in terrestrial ecosystems
}

Daniel J. G. Lahr, Tanja Bosak, Enrique Lara, Edward A. D. Mitchell

The terrestrial cycling of $\mathrm{Si}$ is thought to have a large influence on the terrestrial and marine primary production, as well as the coupled biogeochemical cycles of $\mathrm{Si}$ and $\mathrm{C}$. Biomineralization of silica is widespread among terrestrial eukaryotes such as plants, soil diatoms, freshwater sponges, silicifying flagellates and testate amoebae. Two major groups of testate (shelled) amoebae, arcellinids and euglyphids, produce their own silica particles to construct shells. The two are unrelated phylogenetically and acquired biomineralizing capabilities independently. Hyalosphenids, a group within arcellinids, are predators of euglyphids. We demonstrate that hyalosphenids can construct shells using silica scales mineralized by the euglyphids. Parsimony analyses of the current hyalosphenid phylogeny indicate that the ability to "steal" euglyphid scales is most likely ancestral in hyalosphenids, implying that euglyphids should be older than hyalosphenids. However, exactly when euglyphids arose is uncertain. Current fossil record contains unambiguous euglyphid fossils that are as old as 50 million years, but older fossils are scarce and difficult to interpret. Poor taxon sampling of euglyphids has also prevented the development of molecular clocks. Here, we present a novel molecular clock reconstruction for arcellinids and consider the uncertainties due to various previously used calibration points. The new molecular clock puts the origin of hyalosphenids in the early Carboniferous ( 370 mya). Notably, this estimate coincides with the widespread colonization of land by Si-accumulating plants, suggesting possible links between the evolution of Arcellinid testate amoebae and the expansion of terrestrial habitats rich in organic matter and bioavailable Si. 
1 Title: The Phanerozoic diversification of silica-cycling testate amoebae and its possible links to

2 changes in terrestrial ecosystems

3 Manuscript submitted to peerJ as Research Article

4 Authors: Daniel J. G. Lahr¹, Tanja Bosak², Enrique Lara ${ }^{3}$ and Edward A. D. Mitchell3,4

5 Running Title: Silica biomineralization in early eukaryotes

\section{Affiliations:}

71 - Dept. of Zoology, Institute of Biosciences, University of São Paulo, Rua do Matão, travessa

8 14, São Paulo, Brazil

92 -Department of Earth, Atmospheric and Planetary Sciences, Massachusetts Institute of

10 Technology, 77 Massachusetts Avenue, E25-649, Cambridge, MA 02139

113 - Laboratory of Soil Biology, University of Neuchatel, Rue Emile Argand 11, CH-2000

12 Neuchatel, Switzerland

134 - Jardin Botanique de Neuchâtel, Chemin du Perthuis-du-Sault 58, CH-2000 Neuchâtel,

14 Switzerland

16 Corresponding author: Daniel J. G. Lahr dlahr@ib.usp.br , Phone: +55 (11) 30910948, Fax

$17+55(11) 30917513$ 
ABSTRACT The terrestrial cycling of $\mathrm{Si}$ is thought to have a large influence on the terrestrial and marine primary production, as well as the coupled biogeochemical cycles of $\mathrm{Si}$ and C. Biomineralization of silica is widespread among terrestrial eukaryotes such as plants, soil diatoms, freshwater sponges, silicifying flagellates and testate amoebae. Two major groups of testate (shelled) amoebae, arcellinids and euglyphids, produce their own silica particles to

24 construct shells. The two are unrelated phylogenetically and acquired biomineralizing capabilities independently. Hyalosphenids, a group within arcellinids, are predators of euglyphids. We demonstrate that hyalosphenids can construct shells using silica scales mineralized by the euglyphids. Parsimony analyses of the current hyalosphenid phylogeny indicate that the ability to "steal" euglyphid scales is most likely ancestral in hyalosphenids, implying that euglyphids should be older than hyalosphenids. However, exactly when euglyphids arose is uncertain. Current fossil record contains unambiguous euglyphid fossils that

31 are as old as 50 million years, but older fossils are scarce and difficult to interpret. Poor taxon 32 sampling of euglyphids has also prevented the development of molecular clocks. Here, we present a novel molecular clock reconstruction for arcellinids and consider the uncertainties due

34 to various previously used calibration points. The new molecular clock puts the origin of hyalosphenids in the early Carboniferous ( 370 mya). Notably, this estimate coincides with the widespread colonization of land by Si-accumulating plants, suggesting possible links between the evolution of Arcellinid testate amoebae and the expansion of terrestrial habitats rich in organic matter and bioavailable Si.

Key Words: Microbial eukaryote evolution, silica biomineralization, silica cycle, molecular dating, carbon and silica cycles link 


\section{Introduction}

$\mathrm{Si}$ is a major rock-forming element with a cycle that influences the growth of primary producers and carbon burial in the oceans (Sarmiento, 2013). Over geological time scales, the biogeochemical cycles of carbon and silica are linked through the weathering of continents, which dissolves Si from rocks and delivers it to the oceans (Wilkinson \& Mitchell, 2010). On shorter time scales, Si cycles vigorously in soils and forms a soil pool that is $2-3$ orders of magnitude larger than the Si pool in living terrestrial biomass (Cornelis et al., 2011). Thus, plantmicrobe-mineral interactions that control this sizeable pool of soil Si ultimately control the availability of dissolved Si and the delivery of Si to the oceans (Conley, 2002). Plants are thought to be the major contributors to the terrestrial cycling of Si because they can promote the weathering of rocks, accumulate Si from the soil solution and biomineralize amorphous Si in the form of phytoliths (Alexandre et al., 1997; Cornelis et al., 2011). Phytoliths released from dead plant matter can form a pool with a lower turnover rate relative to other forms of biogenic silica (Alexandre et al., 1997). This pool comprises more than $90 \%$ of biogenic Si delivered to rivers (Cary et al., 2005) and is the main source of reactive Si in soils. Research in the past three decades has revealed much about the role of plant-derived biogenic $\mathrm{Si}$ in the terrestrial cycling of Si (Conley, 2002). In contrast, the contribution and the long term history of Si-biomineralizing microbial groups in terrestrial ecosystems are less well understood (Wilkinson \& Mitchell, 2010). Many microbial eukaryotes use silica to build external and internal skeletons, and have molecular mechanisms for Si uptake. Up to 77 genes regulated by silicic acid in the diatom

Phaeodactylum tricornutum have orthologs in the genomes of other eukaryotes, including Opisthokonts, Viridiplantae and other "Chromalveolates” (Sapriel et al., 2009); see also Figure 1). The genes implicated in silica metabolism may have been exchanged among eukaryotic clades through lateral gene transfer, as demonstrated for choanoflagellates and diatoms (Marron et al., 2013). In terrestrial systems, testate amoebae (i.e. amoebae that construct shells) 
67 are among the most abundant and conspicuous organisms that use silica. The existing studies show that: 1) testate amoebae can contribute up to $10 \%$ of biogenic silica in some tropical soils and rivers (Cary et al., 2005); and 2) the annual incorporation of Si by testate amoebae can in some cases match the amounts of Si released by plant phytoliths (Aoki, Hoshino \& Matsubara, 71 2007; Wilkinson, 2008; M. Sommer, 2012; Puppe et al., 2014). These observations, as well as 72 the long evolutionary history of testate amoebae (Lahr, Grant \& Katz, 2013), suggest a role for testate amoebae in the terrestrial silica cycle and motivate this study.

There are several groups of unrelated testate amoebae. The two most prevalent and abundant in terrestrial environments are the euglyphid and the arcellinid testate amoebae. Both inhabit the same environments -bodies of fresh water, soils, peatlands and other humid microhabitats - and have approximately the same sizes, with the majority of species being between 30-300 $\mu \mathrm{m}$ long or wide. However, the two groups are vastly divergent genetically and historically. Euglyphids include about 800 species and are in the super group Rhizaria (Figure 1). These organisms produce thin, pointed, non-anastomosed pseudopods and almost all extant lineages in the group are silica biomineralizers. Thus, biomineralization is likely ancestral

82 in the group. Owing to the preservation of siliceous shells, euglyphids have a reliable fossil

83 record that goes back at least 30-50 million years (Foissner \& Schiller, 2001; Barber, Siver \&

84 Karis, 2013). The arcellinid testate amoebae encompass about 2000 species and are in the

85 super group Amoebozoa (Figure 1). These amoebae produce rounded, blunt pseudopods and

86 have a great diversity of shell compositions - organic, agglutinated and biomineralized. The

87 fossil record of arcellinids is much older than that of euglyphids, and there is consensus that

88 some vase shaped microfossils dating back to the Neoproterozoic (ca. 750 mya) belong to the

89 arcellinids (Porter \& Knoll, 2009; Bosak et al., 2011; Lahr, Grant \& Katz, 2013; Strauss et al., 90 2014). 
Biomineralization of silica in testate amoebae occurs in many different ways. The shell

92 is always constructed shortly before cell division: a new shell is produced through the aperture

93 of the older shell. After cell division, one daughter cell stays in the old shell and the other

94 daughter cell inherits the new shell (Hedley \& Ogden, 1974). Most euglyphids produce silica

95 scales in the cytoplasm, presumably taking up dissolved $\mathrm{Si}$ and depositing it as amorphous

96 silica via silica deposition vesicles (Hedley \& Ogden, 1974; Anderson, 1994; Gröger, Lutz \&

97 Brunner, 2008). The scales, which are typically shorter than $10 \mu \mathrm{m}$ and thinner than $2 \mu \mathrm{m}$, are

98 then used as building blocks to construct the shell. The specific literature refers to these types of

99 building blocks produced by testate amoebae as idiosomes. A small number of arcellinids use a

100 similar strategy - Lesquereusia, Netzelia, and especially Quadrulella (Figure 2A) are three

101 genera known to produce silica idiosomes (Anderson, 1987, 1989, 1994; Meisterfeld, 2002).

102 Netzelia is able to precipitate idiosomes, but is also known to deposit silica around ingested

103 particles, including starch and various minerals, and then use these particles to build the

104 daughter shell (Anderson, 1987, 1989). Quadrulella, on the other hand, produces its shell

105 entirely of square siliceous idiosomes. Many arcellinids use siliceous particles and mineral

106 grains scavenged from the environment as unmodified building blocks named xenosomes

107 [Difflugia (Figure 2B) and Heleopera are well-known examples (Meisterfeld, 2002; Châtelet,

108 Noiriel \& Delaine, 2013)]. Others are able to lightly modify siliceous particles either by

109 dissolution or deposition (e.g. Nebela (Figure 2C) and related genera [Padaungiella, Argynnia

110 (Figure 2D)], as well as the insertae sedis Lesquereusia (Anderson, 1987, 1989).

111 Both classical and modern studies report the usage of euglyphid scales by arcellinid

112 amoebae of the Hyalospheniidae family (Leidy, 1879; Penard, 1902; Deflandre, 1936; Douglas

$113 \&$ Smol, 2001; Meisterfeld, 2002). These amoebae reportedly obtain silica plates by preying on

114 euglyphids, and then use the stolen scales to build the shell (Deflandre, 1936) - a phenomenon

115 we name kleptosquamy (Figure 3). Here, we record several stages of this phenomenon in 
116 Padaungiella lageniformis that preys upon Euglypha sp. Next, we ask whether kleptosquamy is

117 ancestral in the hyalosphenid testate amoebae and use this to determine the order in which

118 hyalosphenids and euglyphids emerged. To better time the rise of biomineralization in

119 hyalosphenids, we also provide a novel molecular clock reconstruction of the arcellinids. Finally,

120 we discuss the implications of the revised molecular clock in light of broader evolutionary and

121 biogeochemical trends.

\section{Material \& Methods}

123 Microscopical observations

124 Samples of Sphagnum sp. were collected in Les Pontins peat bog in Canton Bern,

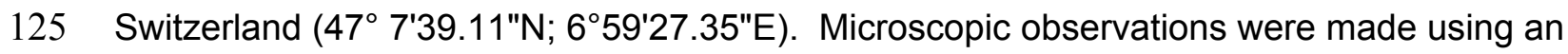

126 Utermöhl chamber (Cat \#435025, HydroBios, Germany) on an Olympus IX81 inverted

127 microscope equipped with oil immersion Differential Interference Contrast optics (20x-40x-60x-

128 100x). All images were recorded by an Olympus DP-71 camera.

129 Ancestral state reconstructions

130 We have performed ancestral state reconstructions on the topologies from molecular

131 reconstructions of two recently published phylogenies (Kosakyan et al., 2012; Oliverio et al.,

132 2014). Each reconstruction is based on a distinct set of molecular data (Cox1 and SSU rDNA

133 respectively). Ancestral state reconstruction was performed in the program Mesquite (Maddison

134 \& Maddison, 2007) using parsimony as an optimality criterion, for the single character

135 kleptosquamy, with possible states present, absent or unknown.

136 Molecular clock reconstructions

Molecular clock reconstructions (MCR) were performed using PhyloBayes 3.3 (Lartillot, 
138 Lepage \& Blanquart, 2009). We used the final tree and alignment for SSU rDNA small subunit

139 ribosomal gene published by Lahr, Grant \& Katz (2013) as a tree onto which we calculated

140 divergence times. Calibration points were the 6 opisthokont fossils also used by Parfrey et al.

141 (Parfrey et al., 2011), whereas the Arcellinida calibration point is based on the fossil

142 Paleoarcella athanata (type specimen HUPC \#62988), described in Porter et al. (2003). The

143 dating of sedimentary rock for this fossil was an ash bed 2 meters above the fossils, calculated

144 by U-Pb zircon chronology (Karlstrom et al., 2000) (Table 1). The opisthokont fossils used by

145 Parfrey et al (2011) are congruent with those proposed and justified for animals by Benton et al.

146 (2015) With additional data present in current tree, it was possible to use the Chuar group

147 fossils as a calibration point for the actual last common ancestor of arcellinids (Porter \& Knoll,

148 2000), rather than the divergence between arcellinids and other naked amoebae, as in Parfrey

149 and colleagues (2011). One alternative run was also generated incorporating the three

150 additional Meso- and Cenozoic fossils as calibration points within the Arcellinida, as suggested

151 by Fiz-Palacios, Leander \& Heger (2014): origin of the Centropyxis genus [termed "node B" in

152 Fiz-Palacios et al. (2014)] was set to the split between Hyalosphenia papilio and Arcella

153 hemisphaerica, with lower and upper bounds at 736-220 mya, origin of hyalosphenids ("node C")

154 was set to the split between Padaungiella lageniformis and Hyalosphenia elegans with soft

155 bounds at 736-100mya; origin of genus Arcella ("node D"), calibrated the clade containing $A$.

156 hemisphaerica and $A$. vulgaris WP with soft bounds at 105-100mya. We did not include the

157 fourth calibration point suggested by Fiz-Palacios and colleagues (Lesquereusia - Difflugia

158 divergence) because the Lesquereusia SSU rDNA is not available. Fortunately, Fiz-Palacios

159 and colleagues have tested their dataset for sensitivity to this particular calibration point and

160 have determined that its inclusion does not significantly modify the final result (Fiz-Palacios,

161 Leander \& Heger, 2014). We have performed MCRs by running two independent chains with a

162 burn-in factor of 100 until the effective size of samples was above 50 and the maximum

163 discrepancy between chains was below 0.3. These parameters are suggested as values for an 
164 "acceptable run" by the PhyloBayes manual. We used soft constraints on the calibration dates

165 to account for uncertainty in the fossil dates as advocated by several researchers (e.g.,

166 Donoghue \& Benton, 2007; Parfrey et al., 2011). The use of soft constraints requires a model of

167 birth-death for the prior on divergence times. We performed reconstructions using both the

168 GTR and the CAT-GTR models for nucleotide substitutions. We have performed MCR using

169 three distinct models for rate distributions: two auto correlated models (CIR and lognormal) as

170 well as the uncorrelated gamma multipliers model. We performed comparisons for model fit by

171 computing Bayes Factors by thermodynamic integration under the normal approximation, as

172 discussed in Phylobayes 3.3 manual, and recommended in Lartillot and Phillipe (2006). In order

173 to do so, a variance-covariance matrix was obtained using the program estbranches [part of

174 multdivtime package (Thorne \& Kishino, 2003)], with input parameters calculated in baseml [part

175 of the PAML package (Yang, 2007)], following instructions by Rutschmann (2005).

\section{Results}

177 Microscopical observations

178 An individual Padaungiella lageniformis was isolated while preying upon a specimen of

179 Euglypha sp. The Euglypha cytoplasm had been almost completely ingested at the stage of

180 isolation (Figure 3A, B, C). We observed the $P$. lageniformis removing and ingesting siliceous

181 plates from the prey organism's shell for around 10 minutes (Figure 3D). Immediately

182 afterwards, the individual deposited siliceous plates in the inner part of the "neck" of its shell,

183 parallel to the aperture (Figure 3E) and moved large cytoplasmic debris in the same direction

184 (Figure 3E,F). The organism was constructing a plug in the aperture, which became visible at

185 the end of this activity that lasted for approximately one hour. There was no indication that any

186 of the plates were dissolved in the cytoplasm: all previously ingested plates were kept intact and

187 moved towards the aperture. After one hour, the amoeba added multiple additional layers to the 
188 previously laid down barrier (Figures 3G, H, I). Though the scales formed most of the barrier,

189 other types of debris were added as well. After about two hours of actively plugging the

190 aperture, the amoeba encysted, presumably with digestive function (Figures 3J, K). The

191 amoeba remained encysted for at least two more hours. Resumed observations approximately

19212 hours later revealed that the amoeba had emerged from the digestive cyst and re-ingested

193 all siliceous plates (Figure L). However, the organism had discarded the yellowish-brown types

194 of debris (Figure 3L). The siliceous plates did not appear to be separated from any other

195 cytoplasmic structures by membranes. Many gathered around the nucleus at times. Two days

196 after the initial ingestion, the amoeba went into a second resting cyst (it is relevant to note that

197 the amoeba was maintained in an environmental sample and had access to ample food items),

198 where it remained for over 24 hours, but did not exhibit other relevant changes. We

199 discontinued observations approximately 80 hours after initial observation (4 days).

Ancestrality of kleptosquamy

202

Observations of kleptosquamy and the associated behavioral attitudes enable evolutionary interpretations in other closely related hyalosphenid testate amoebae. The conspicuous plug made of scales created by Padaungiella, as well as the presence of modified euglyphid scales in the shell is observed in most other hyalosphenids, including the genera: Apodera, Certesella (Meisterfeld, 2002), Porosia (Figure 4A), and finally Nebela (Figure 4B).

207 One other genus has shells that contain small, possibly siliceous scales with undetermined origin: Physochila and Argynnia (Figure 2D, (Vucetich, 1974)) were shown not to be closely related to hyalosphenids (Gomaa et al., 2012). Considering the most current molecular data

210 available, Padaungiella is a basal lineage (Lara et al., 2008; Heger et al., 2011; Gomaa et al.,

211 2012; Kosakyan et al., 2012; Lahr, Grant \& Katz, 2013). Other four genera (Apodera, Certesella, 
212 Porosia, Nebela) are able to re-use scales obtained from euglyphids and three others

213 (Quadrulella, Hyalosphenia and Alocodera) do not. We have performed a parsimony based

214 ancestral reconstruction of character states in both topologies available (based on mitochondrial

215 and nuclear genes, Figure 5). Under any of the two scenarios scenario, kleptosquamy appears

216 in the ancestral hyalosphenid, and is lost twice: once in the genus Quadrulella, which

217 biomineralizes its own silica scales and once in Hyalosphenia, which builds entirely

218 proteinaceous scales without mineral parts. In the scenario of Oliverio et al. (2014),

219 kleptosquamy is lost 3 times because the genus Hyalosphenia is not monophyletic. The non-

220 monophyly of Hyalosphenia has no effect on the ancestral character state for hyalosphenids as

221 a whole (Figure 5).

222

223

224

225

226

227

228

229

230

231

232

233

234

235

Molecular clock reconstructions

To determine the origin of hyalosphenids, we generated a dated tree for the arcellinids

(Figure 6, left). In order to do so, we used the previously established opisthokont calibration points and a conservative calibration point for the minimum date of origin of the Arcellinida - this calibration point is used conservatively as calibrating the entire Arcellinida, as opposed to the less inclusive family Arcellidae as suggested by affinities in the original description (Porter, Meisterfeld \& Knoll, 2003). In this reconstruction, we used the uncorrelated gamma multipliers model for the distribution of divergence times. This is because in our model fit analyses, this model yielded the largest Bayes Factor (logBF interval of 18.7-26.9, against 12.8-14.5 for CIR model and 16.6-24.7 for lognormal model). The Bayes Factor is one of many proposed methods to measure the appropriateness of a given model for the data at hand, and a larger BF indicates a better model fit (Lartillot \& Philippe, 2006). Hence, all results discussed are based on that model. The reconstruction ran for circa 55,000 cycles until convergence between the two chains was achieved. 
Our reconstruction stands in sharp contrast with another recent molecular clock reconstruction of the arcellinids (Fiz-Palacios, Leander \& Heger, 2014). The two most likely reasons for this are: 1) although Fiz-Palacios and colleagues used a part of the same dataset used here, we focused on the SSU rDNA partition and not on the protein coding partition; 2) we included mostly opisthokont fossils as calibration points, but Fiz-Palacios and colleagues used a number of Meso- and Cenozoic microfossils as calibration points for internal families of arcellinids. To test the influence of these hypotheses, we implemented the calibration points suggested by Fiz-Palacios in our framework. This yielded an additional tree (Figure 6, right).

244 This tree is very similar to the tree obtained by Fiz-Palacios and colleagues, with all origins of 245 groups tending to appear at younger dates. For instance, the origin of arcellinids as a whole 246 shifts from 944 mya to 600 mya using the Meso- and Cenozoic fossils. This is representative of 247 a general trend throughout the tree. Therefore, the distinct dates obtained in the reconstruction 248 presented in Figure 5 (left) probably do not stem from focusing on the SSU rDNA partition, but 249 rather from the use of distinct calibration points. Hence, the interpretation of fossils is 250 paramount in defining which result is more likely to reconstruct the actual history of Arcellinida.

\section{Discussion}

Kleptosquamy can be inferred as an ancestral character state in hyalosphenids (Figure 5), i.e., the last common ancestor of all extant hyalosphenids was able to re-use euglyphid scales. Hyalosphenid biology is not well understood, because most attempts to culture these organisms have failed. Strains that have been maintained for a certain time (Nebela collaris) had to be fed with fast-growing species of euglyphids, such as Euglypha hyalina (Ralf Meisterfeld, personal communication). For instance, one cannot say with certainty whether a

258 hyalosphenid is able to construct the shell without any euglyphid scales. This caveat undermines the interpretation of klepstosquamy as ancestral in the group, for this reason, we clearly establish that our working hypothesis is that scaled euglyphids appeared before 
261 hyalosphenids.

262 The fossil record of euglyphids is quite sparse and does not currently allow accurate 263 timing of their evolution. The very well documented microfossils of Scutiglypha from

264 diatomaceous earth demonstrate that modern genera have existed for at least 15 million years 265 (Foissner \& Schiller, 2001). More recently, Eocene microfossils have unambiguously pushed 266 the fossil record of euglyphids back to 50 million years ago (Barber, Siver \& Karis, 2013), 267 including members of the genus Scutiglypha (Euglyphidae). Older records of shells are much 268 more difficult to interpret, as the conditions of shell preservation make the separation between 269 arcellinids and euglyphids ever more difficult: because of intense convergence, pseudopods 270 would be the only reliable way of separating arcellinids and euglyphids, but these are usually 271 not preserved in the fossil record (Bosak et al., 2011; Lahr et al., 2014). For instance, some 272 vase shaped microfossils described from the Chuar group, especially Melicerion poikilon, 273 Bonniea spp. and Bombycion micron have morphological characteristics that are compatible 274 with euglyphid testate amoebae: the typical vase shape, thin walls, terminal aperture,

275 homogeneously shaped and sized scales and an apparent siliceous composition. However, an 276 arcellinid origin cannot be excluded, Quadrulella, a modern arcellinid, shares all those features 277 (Porter \& Knoll, 2000; Porter, Meisterfeld \& Knoll, 2003). Hence, new discoveries of 278 exceptionally preserved and properly described arcellinid and euglyphid fossils are necessary to 279 inform interpretations of origin and diversification (Bosak et al., 2011; Dalton et al., 2013; Fiz280 Palacios, Leander \& Heger, 2014; Strauss et al., 2014). The dated reconstruction presented here uses a single-locus and external calibration 282 points to the arcellinids and places the origin of hyalosphenids in the Paleozoic (about 370 mya, 283 with a 95\% confidence interval that extends from the Neoproterozoic to Triassic). This is in 284 marked contrast to the recent reconstruction of arcellinid history by Fiz-Palacios, Leander \& 285 Heger (2014), which placed the origin of hyalosphenids in the Cretaceous, about 130 mya (with 
a 95\% confidence interval between the Devonian and the Eocene). These authors used a very similar dataset, but included both the SSU rDNA and five additional protein coding genes (both analyses are based on the dataset published by Lahr et al., 2013). The 240 million year difference between the two reconstructions is significant and may lead to very distinct implications. The use of the same calibration points as Fiz-Palacios and colleagues, combined with our search strategy, produced a tree that is very similar to the results of Fiz-Palacios et al. and estimate a Cretaceous rise of hyalospheniids. The additional calibration points used are controversial, some are based on fossils whose descriptions have not clearly established syngenicity with the matrix and may be contaminants (Farooqui et al., 2010; Kumar, 2011); others come from amber and the identity of organisms is established using optical microscopy alone (Schmidt, Schönborn \& Schäfer, 2004; Schmidt et al., 2006; Girard et al., 2011). The inclusion of these fossils as calibration points led to an interesting scenario interpreted by FizPalacios et al. (2014): that hyalosphenids are an ancient lineage that diversified when the complex peatland environments became available. The caveat is that many aspects of the identities of fossils used as calibration points remain to be clarified - this does not mean that the 301 interpretations are incorrect. amoebae including hyalospheniids, the aquatic Arcella + Netzelia clade, as well as the soil dwelling Trigonopyxis + Bullinularia clade have diversified after mid-Devonian. In contrast to the preceding periods, when plant cover was restricted to moist habitats, the Late Devonian and the

306 Carboniferous saw the diversification of plants that were well adapted to life on land, with

307 deeper roots and soil forming capabilities (e.g., (Gibling \& Davies, 2012; Kenrick et al., 2012)).

308 These plants formed extensive forests, established their own, humid environments, and 309 produced abundant organic matter as well as soils (Kenrick et al., 2012), matching the

310 appearance of the Bullinularia clade. These evolutionary events likely influenced the Si cycling 
311 on land as well due to two main factors: 1) The root systems of the Late

312 Devonian/Carboniferous plants are thought to have promoted silicate weathering (e.g., (Algeo,

313 Scheckler \& Maynard, 2001)), and 2) Tree-like Lycopodiophyta, Equisetales and liverworts,

314 plants whose modern relatives can accumulate as much or more Si than grasses (Hodson et al.,

315 2005), were abundant in forest ecosystems. Our new molecular clock reconstruction and the

316 coinciding sequence of evolutionary and ecological changes that have been documented in the

317 fossil record inspire questions. Did the release of Si from plants and the accumulation of Si in

318 the plates of biomineralizing testate amoebae as well as in various predatory species strengthen

319 the links between the $\mathrm{C}$ and the Si cycles on land? The annual rate of biosilification by testate

320 amoebae was shown to be of the same order as the uptake rate by trees (Aoki, Hoshino \&

321 Matsubara, 2007; M. Sommer, 2012; Puppe et al., 2014) and the size of the Si pool in testate

322 amoebae increases with vegetation development in some early ecosystem successions (Puppe

323 et al., 2014).

324 To move forward from here we need to i) better understand Si metabolism across protist

325 groups, including deeper understanding of physiological aspects; ii) obtain reliable fossil

326 evidence for the appearance and diversification of Si-metabolizing lineages; iii) improve the

327 molecular clock by expanding the molecular database, using appropriate numerical models and

328 carefully checking the reliability of the fossil record, iv) improve constraints on the contribution of

329 Si-precipitating organisms to the cycling of Si and C in terrestrial systems. The combination of

330 these efforts is challenging, but can be met with a combination of approaches including

331 molecular phylogeny, biogeochemistry, and paleontology.

\section{Data accessibility}

333 Alignments and phylobayes runs will be made available upon acceptance of the article. 


\section{Acknowledgments}

335 We are thankful for the associate editor as well as two reviewers for relevant criticism of the 336 manuscript 


\section{References}

338 Alexandre A., Meunier J-D., Colin F., Koud J-M. 1997. Plant impact on the biogeochemical 339 cycle of silicon and related weathering processes. Geochimica et Cosmochimica Acta 61:677-682.

Algeo TJ., Scheckler SE., Maynard JB. 2001. Effects of the Middle to Late Devonian spread of vascular land plants on weathering regimes, marine biotas, and global climate. Plants invade the land: Evolutionary and environmental perspectives:213-236.

344 Anderson OR. 1987. Fine Structure of a Silica-Biomineralizing Testate Amoeba, Netzelia tuberculata. The Journal of Protozoology 34:302-309.

Anderson OR. 1989. Some observations of feeding behavior, growth, and test particle morphology of a silica-secreting testate amoeba Netzelia tuberculata (Wallich) (Rhizopoda, Testacea) grown in laboratory culture. Archiv für Protistenkunde 137:211221.

Anderson OR. 1994. Cytoplasmic origin and surface deposition of siliceous structures in Sarcodina. Protoplasma 181:61-77.

Aoki Y., Hoshino M., Matsubara T. 2007. Silica and testate amoebae in a soil under pine-oak forest. Geoderma 142:29-35.

Barber A., Siver PA., Karis W. 2013. Euglyphid Testate Amoebae (Rhizaria: Euglyphida) from an Arctic Eocene Waterbody: Evidence of Evolutionary Stasis in Plate Morphology For Over 40 Million Years. Protist 164:541-555.

Benton MJ., Donoghue PC., Asher RJ., Friedman M., Near TJ., Vinther J. 2015. Constraints on the timescale of animal evolutionary history. Palaeontologia Electronica 18:1-106.

Bosak T., Lahr DJG., Pruss SB., Macdonald FA., Dalton L., Matys E. 2011. Agglutinated tests in post-Sturtian cap carbonates of Namibia and Mongolia. Earth and Planetary Science 
362 Cary L., Alexandre A., Meunier J-D., Boeglin J-L., Braun J-J. 2005. Contribution of phytoliths to the suspended load of biogenic silica in the Nyong basin rivers (Cameroon). Biogeochemistry 74:101-114.

Châtelet EA du., Noiriel C., Delaine M. 2013. Three-Dimensional Morphological and

Conley DJ. 2002. Terrestrial ecosystems and the global biogeochemical silica cycle. Global Mineralogical Characterization of Testate Amebae. Microscopy and Microanalysis Biogeochemical Cycles 16:68-1.

Cornelis J-T., Delvaux B., Georg RB., Lucas Y., Ranger J., Opfergelt S. 2011. Tracing the origin of dissolved silicon transferred from various soil-plant systems towards rivers: a review. Biogeosciences 8:89-112.

Dalton LA., Bosak T., Macdonald FA., Lahr DJG., Pruss SB. 2013. Preservational and Morphological Variability of Assemblages of Agglutinated Eukaryotes in Cryogenian Cap Carbonates of Northern Namibia. PALAIOS 28:67-79.

Deflandre G. 1936. Etude monographique sur le genre Nebela Leidy. Ann Protistol 5:201-286.

Donoghue PC., Benton MJ. 2007. Rocks and clocks: calibrating the Tree of Life using fossils and molecules. Trends in Ecology \& Evolution 22:424-431.

Douglas MSV., Smol JP. 2001. Siliceous Protozoan Plates and Scales. In: Smol JP, Birks HJB, Last WM, Bradley RS, Alverson K eds. Tracking Environmental Change Using Lake Sediments. Developments in Paleoenvironmental Research. Springer Netherlands, 265-

383 Farooqui A., Kumar A., Jha N., Pande AC., Bhattacharya DD. 2010. A Thecamoebian 
Assemblage from the Manjir Formation (Early Permian) of Northwest Himalaya, India. E-Journal Earth Science India 3:146-153.

386 Fiz-Palacios O., Leander BS., Heger TJ. 2014. Old Lineages in a New Ecosystem: Diversification of Arcellinid Amoebae (Amoebozoa) and Peatland Mosses. PLoS ONE

Foissner W., Schiller W. 2001. Stable for 15 million years: scanning electron microscope investigation of Miocene euglyphid thecamoebians from Germany, with description of the new genus Scutiglypha. European Journal of Protistology 37:167-180.

Gibling MR., Davies NS. 2012. Palaeozoic landscapes shaped by plant evolution. Nature Geoscience 5:99-105.

Girard V., Néraudeau D., Adl SM., Breton G. 2011. Protist-like inclusions in amber, as evidenced by Charentes amber. European Journal of Protistology 47:59-66.

Gomaa F., Todorov M., Heger TJ., Mitchell EAD., Lara E. 2012. SSU rRNA Phylogeny of Arcellinida (Amoebozoa) Reveals that the Largest Arcellinid Genus, Difflugia Leclerc 1815, is not Monophyletic. Protist 163:389-399.

Gröger C., Lutz K., Brunner E. 2008. Biomolecular Self-assembly and its Relevance in Silica Biomineralization. Cell Biochemistry and Biophysics 50:23-39.

Hedley DRH., Ogden CG. 1974. Adhesion plaques associated with the production of a daughter cell in Euglypha (Testacea; Potozoa). Cell and Tissue Research 153:261-268.

Heger TJ., Pawlowski J., Lara E., Leander BS., Todorov M., Golemansky V., Mitchell EAD. 2011. Comparing Potential COI and SSU rDNA Barcodes for Assessing the Diversity and Phylogenetic Relationships of Cyphoderiid Testate Amoebae (Rhizaria: Euglyphida). Protist 162:131-141. 
407 Hodson MJ., White PJ., Mead A., Broadley MR. 2005. Phylogenetic variation in the silicon $408 \quad$ composition of plants. Annals of Botany 96:1027-1046.

409 Karlstrom KE., Bowring SA., Dehler CM., Knoll AH., Porter SM., Des Marais DJ., Weil AB., 410 Sharp ZD., Geissman JW., Elrick MB., others 2000. Chuar Group of the Grand Canyon:

411 Record of breakup of Rodinia, associated change in the global carbon cycle, and 412 ecosystem expansion by 740 Ma. Geology 28:619-622.

413 Kenrick P., Wellman CH., Schneider H., Edgecombe GD. 2012. A timeline for terrestrialization: 414 consequences for the carbon cycle in the Palaeozoic. Philosophical Transactions of the $415 \quad$ Royal Society of London B: Biological Sciences 367:519-536.

416 Kosakyan A., Heger TJ., Leander BS., Todorov M., Mitchell EAD., Lara E. 2012. COI

417 Barcoding of Nebelid Testate Amoebae (Amoebozoa: Arcellinida): Extensive Cryptic

418 Diversity and Redefinition of the Hyalospheniidae Schultze. Protist 163:415-434.

419 Kumar A. 2011. Acid-resistant Cretaceous thecamoebian tests from the Arabian Peninsula: a 420 suggestion for study of agglutinated rhizopods in palynological slides. Journal of $421 \quad$ Micropalaeontology 30:1-5.

422 Lahr DJ., Laughinghouse HD., Oliverio AM., Gao F., Katz LA. 2014. How discordant 423 morphological and molecular evolution among microorganisms can revise our notions of 424 biodiversity on Earth. BioEssays 36:950-959.

Lahr DJG., Grant JR., Katz LA. 2013. Multigene Phylogenetic Reconstruction of the Tubulinea 426 427 (Amoebozoa) Corroborates Four of the Six Major Lineages, while Additionally Revealing that Shell Composition Does not Predict Phylogeny in the Arcellinida. Protist 428 164:323-339.

429 Lara E., Heger TJ., Ekelund F., Lamentowicz M., Mitchell EAD. 2008. Ribosomal RNA Genes 

159:165-176.

432 Lartillot N., Lepage T., Blanquart S. 2009. PhyloBayes 3: a Bayesian software package for 433 phylogenetic reconstruction and molecular dating. Bioinformatics 25:2286-2288.

434 Lartillot N., Philippe H. 2006. Computing Bayes Factors Using Thermodynamic Integration. $435 \quad$ Systematic Biology 55:195-207.

436 Leidy J. 1879. Fresh-Water Rhizopods of North America. 12:1-327.

437 Maddison WP., Maddison DR. 2007. Mesquite: a modular system for evolutionary analysis.

438 Version 2.75. 2011. URL http://mesquiteproject. org.

439 Marron AO., Alston MJ., Heavens D., Akam M., Caccamo M., Holland PWH., Walker G. 2013.

440 A family of diatom-like silicon transporters in the siliceous loricate choanoflagellates.

441 Proceedings of the Royal Society B: Biological Sciences 280:20122543.

442 Meisterfeld R. 2002. Order Arcellinida Kent, 1880. The illustrated guide to the Protozoa 2:827443 860.

444 M. Sommer HJ. 2012. Si cycling in a forest biogeosystem - the importance of anthropogenic 445 perturbation and induced transient state of biogenic Si pools. Biogeosciences Discussions 9:18865-18906.

447 Oliverio AM., Lahr DJ., Nguyen T., Katz LA. 2014. Cryptic Diversity within Morphospecies of 448 Testate Amoebae (Amoebozoa: Arcellinida) in New England Bogs and Fens. Protist. 449 Parfrey LW., Lahr DJG., Knoll AH., Katz LA. 2011. Estimating the timing of early eukaryotic 450 diversification with multigene molecular clocks. Proceedings of the National Academy of $451 \quad$ Sciences 108:13624-13629.

452 Penard E. 1902. Faune rhizopodique du bassin du Léman... 
453 Porter SM., Knoll AH. 2000. Testate amoebae in the Neoproterozoic Era: evidence from vase454 shaped microfossils in the Chuar Group, Grand Canyon. Paleobiology 26:360-385.

455 Porter SM., Knoll AH. 2009. Testate amoebae in the Neoproterozoic Era: evidence from vase456 shaped microfossils in the Chuar Group, Grand Canyon.

457 Porter SM., Meisterfeld R., Knoll AH. 2003. Vase-Shaped Microfossils from the Neoproterozoic 458 Chuar group, Grand Canyon: a classification guided by modern testate amoebae. Journal of Paleontology 77:409-429.

460 Puppe D., Kaczorek D., Wanner M., Sommer M. 2014. Dynamics and drivers of the protozoic Si 461 pool along a 10-year chronosequence of initial ecosystem states. Ecological Engineering 462 70:477-482.

Rutschmann F. 2005. Bayesian molecular dating using PAML/multidivtime. A step-by-step manual. University of Zurich.

Sapriel G., Quinet M., Heijde M., Jourdren L., Tanty V., Luo G., Le Crom S., Lopez PJ. 2009. Genome-Wide Transcriptome Analyses of Silicon Metabolism in Phaeodactylum tricornutum Reveal the Multilevel Regulation of Silicic Acid Transporters. PLoS ONE 4:e7458.

Sarmiento JL. 2013. Ocean Biogeochemical Dynamics. Princeton University Press.

Schmidt AR., Ragazzi E., Coppellotti O., Roghi G. 2006. A microworld in Triassic amber. Nature 444:835-835.

472 Schmidt AR., Schönborn W., Schäfer U. 2004. Diverse fossil amoebae in German Mesozoic amber. Palaeontology 47:185-197.

474 Strauss JV., Rooney AD., Macdonald FA., Brandon AD., Knoll AH. 2014. 740 Ma vase-shaped 475 microfossils from Yukon, Canada: Implications for Neoproterozoic chronology and 

biostratigraphy. Geology:G35736.1.

477 Thorne JL., Kishino H. 2003. Multidivtime. Available from the authors at http://statgen. ncsu. 478 edu/thorne/multidivtime. html.

479 Vucetich MC. 1974. Comentarios criticos sobre Argynnia Jung, 1942 (Rhizopoda, Testacea). $480 \quad$ Neotropica (La Plata) 20:126-128.

481 Wilkinson DM. 2008. Testate amoebae and nutrient cycling: peering into the black box of soil 482 ecology. Trends in ecology \& evolution 23:596-599.

483 Wilkinson DM., Mitchell EAD. 2010. Testate Amoebae and Nutrient Cycling with Particular $484 \quad$ Reference to Soils. Geomicrobiology Journal 27:520-533.

485 Yang Z. 2007. PAML 4: Phylogenetic Analysis by Maximum Likelihood. Molecular Biology $486 \quad$ and Evolution 24:1586-1591. 
Figure 1 (on next page)

A simplified tree of eukaryotes indicating that biomineralization is a convergent feature.

The main supergroups are indicated by the different colors and the lineages in bold contain biomineralizers. Backbone of tree is based on relationships in Katz (2012), dotted lines represent uncertainty. 


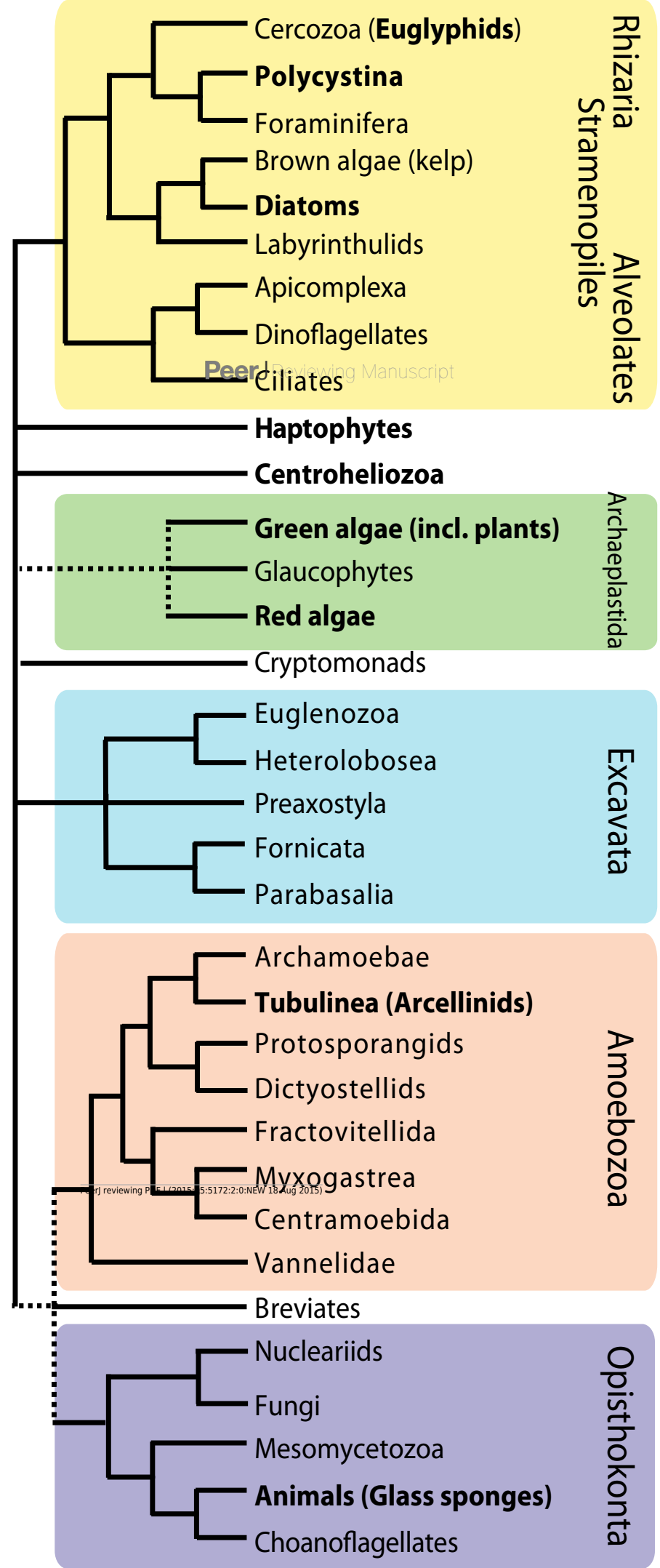




\section{2}

Examples of arcellinids shell composition.

A: Quadrulella subcarinata Gautier-Lièvre, 1957 constructs the shell using square particles of amorphous Si that are endogenously produced from dissolved silica (idiosomes). Specimen from Sphagnum collected in Welgevonden Game Park, Limpopo province, South Africa. B: Difflugia acuminata Ehrenberg builds its shell from agglutinated diverse particles, in this case, the organism used both centric (white arrow) and pennate (black arrow) diatom shells, along with other smaller particles. C: Nebela marginata Penard uses a mixture of particles with some additional biological silica deposition, such as scales scavenged from euglyphids (oval and circular plates as the one indicated by the white arrow), and pennate diatoms (black arrow). D: Argynnia dentistoma, this specimen has used a mixture of flat environmental mineral particles and rounded euglyphid scales to construct the shell. B-D: Specimens from Eugene Penard's collection, deposited at the Natural Museum of Geneva; photos taken by Thierry Arnet - Wikimedia document. Scale bars $30 \mu \mathrm{m}$. 

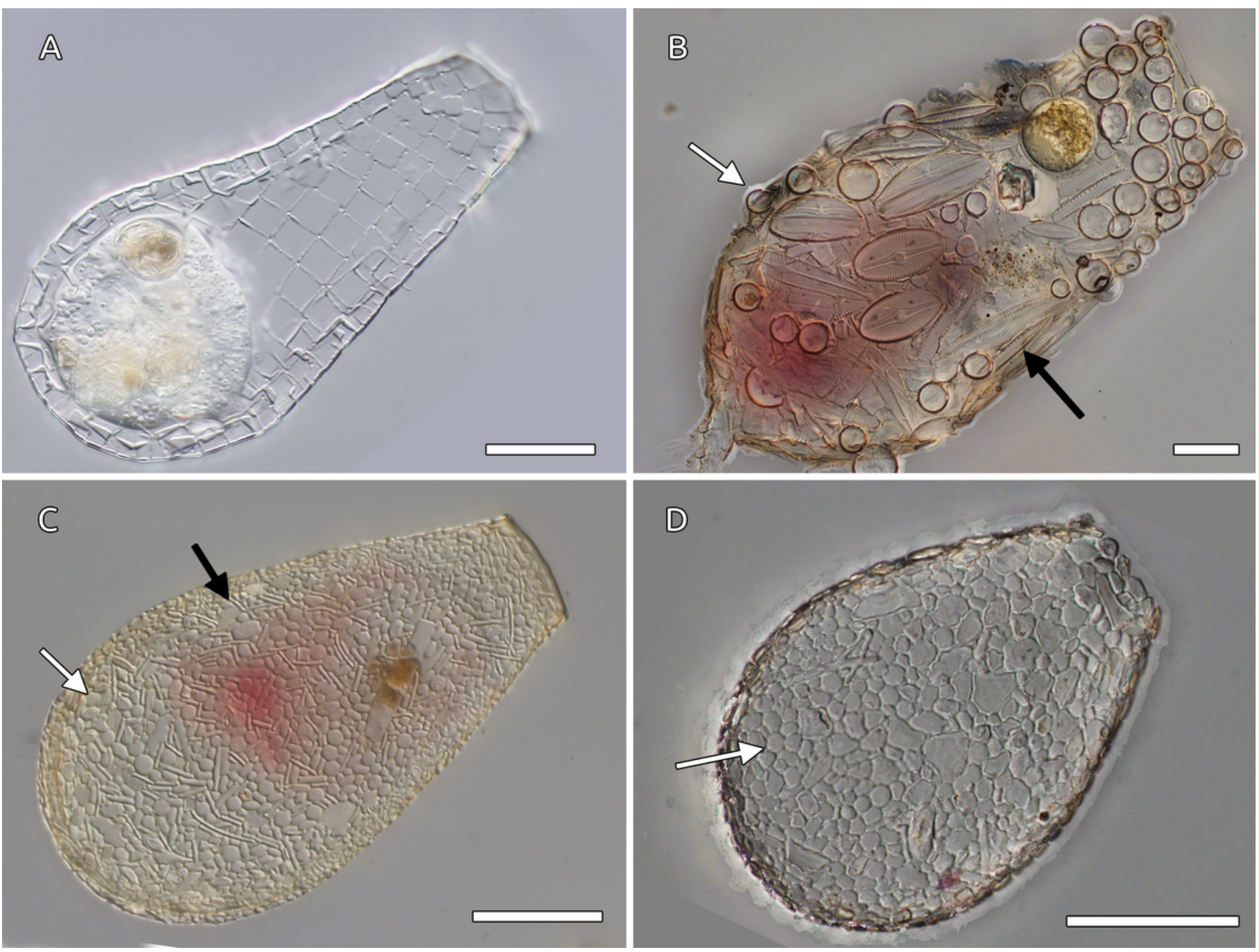
3

An example of kleptosquamy in the arcellinid Apodera vas (larger shell), obtained from predation upon the euglyphid Sphenoderia valdiviana (two smaller individuals).

The two species occur together in Sphagnum magellanicum mosses around Laguna Esmeralda, in Argentinian Tierra del Fuego. The larger scales (arrows) in the test of $A$. vas can clearly be matched to the ones produced by $S$. valdiviana.

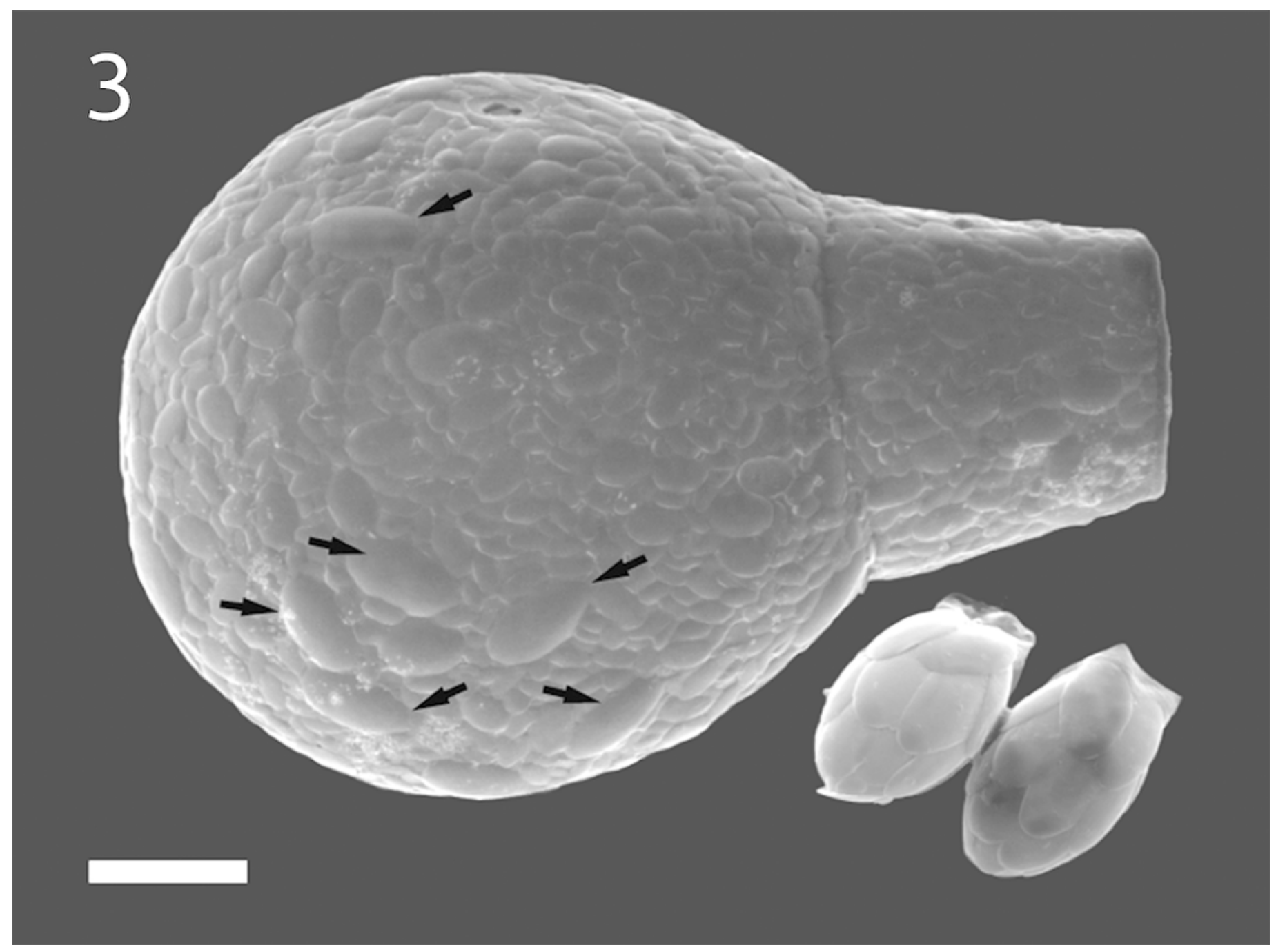




\section{4}

Kleptosquamy in Padaungiella lageniformis.

A: Lateral view of $P$. lageniformis ingesting cytoplasm of Euglypha sp., beginning of observations $(T=0)$. B: View closer to the bottom of the plate, where the teardrop shaped apertural scales of the Euglypha individual are visible (white arrow), and other already ingested plates are in $P$. lageniformis cytoplasm (black arrow, $T=22$ min). C: A distinct optical section from $B$, showing a region in the Euglypha shell where the roughly hexagonal body plates (white arrow) were removed by the $P$. lageniformis, note that here the apertural scales are not present on this side ( $T=22 \mathrm{~min})$. D: Accumulation of plates from Euglypha in the cytoplasmic region of $P$. lageniformis close to the aperture (black arrows), in the cytoplasm, plates are easily when in profile view ( $T=22 \mathrm{~min})$. E: Early stage of apertural plug construction, the $P$. lageniformis has laid down two scales (black arrow) in a parallel orientation to the aperture ( $T=23 \mathrm{~min}$ ). $\mathrm{F}$ : The organism begins to add other debris to the plug (black arrow, $t=24 \mathrm{~min}$ ). $\mathrm{G}$ : Debris particles had been added to the plug, notice vesicles of yellowish-brown material in the cytoplasm (black arrows), these are later added to the plug ( $T=1 \mathrm{~h} 13 \mathrm{~min})$. H: Yellowish-brown debris moves closer to the aperture (black arrows, $T=1 \mathrm{~h} 13 \mathrm{~min}$ ). I: All debris particles finally added to the apertural plug (black arrows, $\mathrm{T}=1 \mathrm{~h} 32 \mathrm{~min})$. J: After apertural plug is finished, the cell goes into a cyst ( $T=1 \mathrm{~h} 52 \mathrm{~min}) . \mathrm{K}$ :

Whole view of digestive cyst ( $T=1 \mathrm{~h} 52 \mathrm{~min})$. L: Emergence of cyst 12 hours later, many scales are visible in the cytoplasm (black arrows), they were recollected from the plug. Other types of particles were discarded. Scale bar $=20 \mu \mathrm{m}(\mathrm{B}-\mathrm{J})$ and $50 \mu \mathrm{m}(\mathrm{A}, \mathrm{K}, \mathrm{L})$. 
PeerJ Reviewing Manuscript

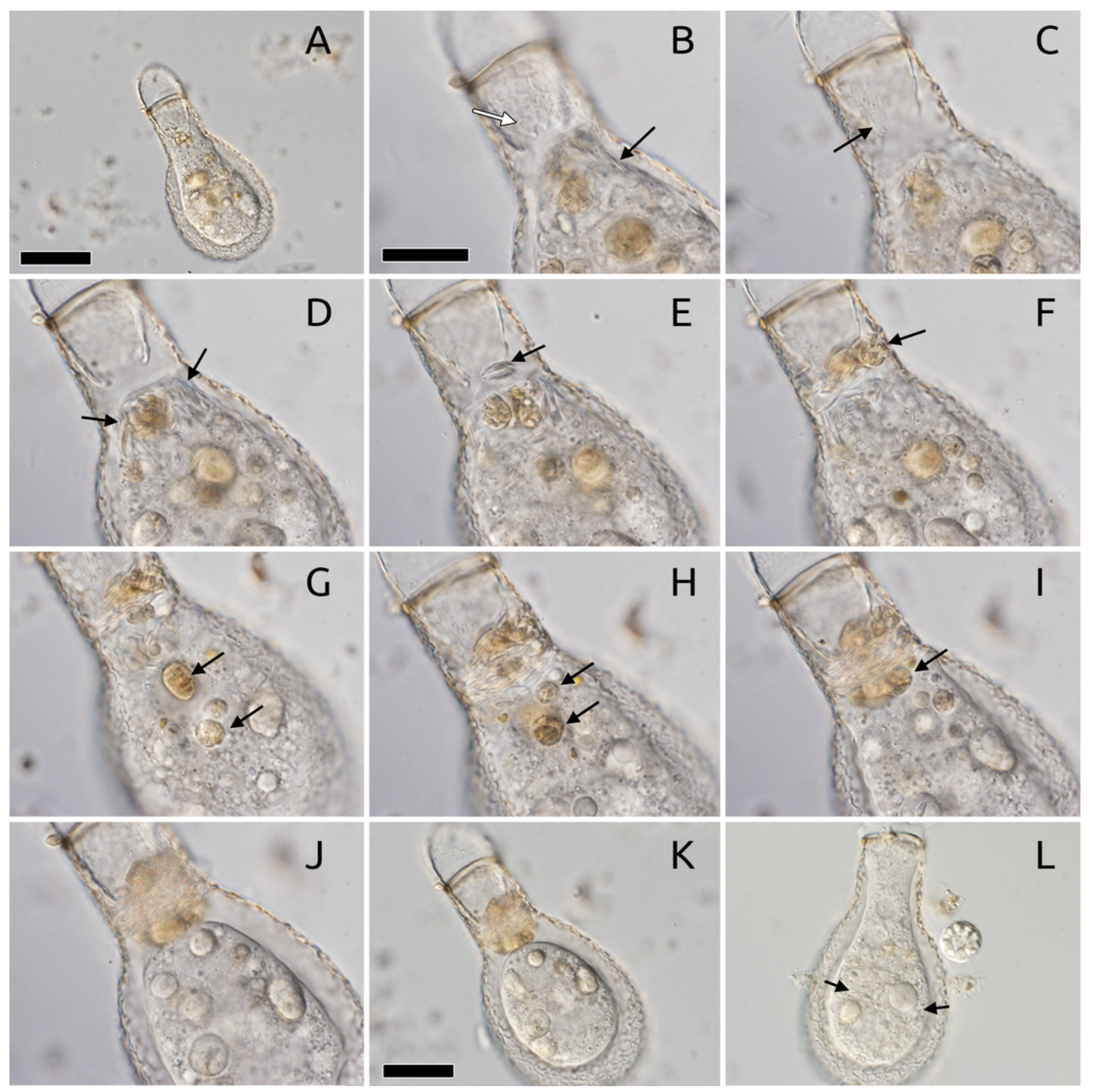




\section{5}

Evidence of kleptosquamy in other hyalosphenid genera.

A: A specimen of Porosia bigibbosa in a digestive cyst, with an apertural plug constructed partly with siliceous scales (white arrows). Specimen from mosses collected on an erratic boulder near the Merdasson river, Neuchâtel, Switzerland. B: A specimen of Nebela marginata, about to enter the digestive cyst, presenting also an apertural plug constructed with a layer of siliceous scales (white arrows), among others. Specimen from Sphagnum collected in Les Pontin bog, Canton Bern, Switzerland. Scale bar $=50 \mu \mathrm{m}$.
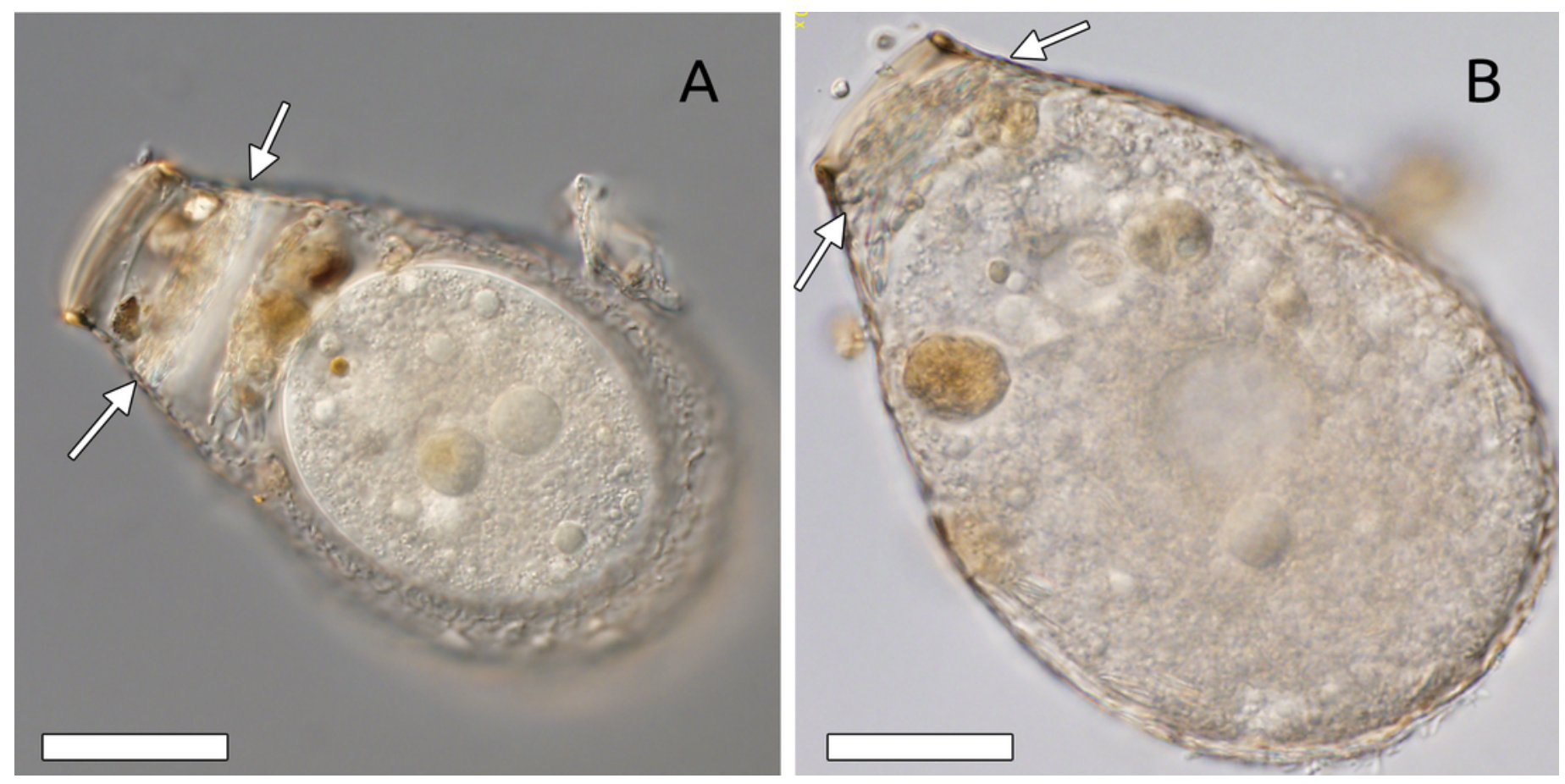
Figure 6 (on next page)

Ancestral state reconstruction of kleptosquamy in the hyalosphenid genera.

The backbone of each cladogram is one of two most current hyalosphenid phylogenies, based on distinct sets of genes. Colors along the tree branches represent how states changed through evolution for this character. 
Figure 7 (on next page)

Comparison between dated phylogenies of Arcellinida based on molecular clock reconstructions using distinct sets of calibration points.

Both reconstructions were based on a 109 taxon, 914 positions alignment. Taxa that are not relevant for the present discussion have been collapsed for clarity. The reconstruction on the left uses a single arcellinid calibration point (indicated), and other 5 calibration points inside the Opisthokonta. The reconstruction on the right uses the previous 6 calibration points plus 3 additional arcellinid calibration points. Although the mean value for node times can be quite different, both reconstructions are within the $95 \%$ confidence interval of each other (indicated by blue bars). 


\section{Table $\mathbf{1}$ (on next page)}

Summary of calibration points used of molecular clock reconstructions. Dates are in millions of years. 
1 Table 1: Summary of calibration points used of molecular clock reconstructions. Dates are in 2 millions of years.

3

\begin{tabular}{|c|c|c|c|c|}
\hline Clade & Fossil & Taxa used for delimitation & $\begin{array}{l}\text { Max } \\
\text { date }\end{array}$ & $\begin{array}{l}\text { Min } \\
\text { date }\end{array}$ \\
\hline Amniota & Westlonthiana & $\begin{array}{l}\text { Gallus gallus and Homo } \\
\text { sapiens }\end{array}$ & 400 & 328.3 \\
\hline Ascomycetes & Paleopyrenomycetes & $\begin{array}{l}\text { S.s pombe and } P \text {. } \\
\text { chrysosporium }\end{array}$ & 1000 & 400 \\
\hline Endopterygota & Mecoptera & $\begin{array}{l}\text { A. mellifera and } D \text {. } \\
\text { melanogaster }\end{array}$ & 350 & 284.4 \\
\hline Animals & sponge biomarkers & O. carmella and C. capitata & 3,000 & 632 \\
\hline Bilateria & Kimberella & B. floridae and C. capitata & 630 & 555 \\
\hline Vertebrates & Haikouichthys & $B$. floridae and $H$. sapiens & 555 & 520 \\
\hline Arcellinida & Paleoarcella & $\begin{array}{l}\text { A. hemisphaerica and } H \text {. } \\
\text { sphagni }\end{array}$ & 3,000 & 736 \\
\hline
\end{tabular}

